\title{
ANAL YSES ON THE EFFECT OF MAGNETIC INDUCTION ATTENUATION ON THE CURRENT DISTRIBUTION IN A FARADAY MHD GENERATOR
}

\author{
Le Chi Kien \\ Ho Chi Minh City - University of Technical Education \\ (Manuscript Received on December 24 $4^{\text {th }}$, 2012, Manuscript Revised April 24 ${ }^{\text {th }}$, 2013)
}

ABSTRACT: This paper examines the dependence of the attenuation of magnetic induction on the current distribution etc. in the exit regions of the Faraday type non-equilibrium plasma MHD generator by a two-dimensional calculation. The numerical analyses are made for an example of the cesium-seeded helium. As a result, a reasonable magnetic induction attenuation can make the distribution of current very uniform near the exit region of generator channel and has little influence on the current distribution in the middle part of generator, and the output electrodes can be used without great ballast resistors. Also the inside resistance of the exit region and the current concentration at the exit electrode edges decrease with the attenuation of magnetic flux density. By the author's examination, it is made clear that the exit electrodes of the diagonal Faraday type non-equilibrium plasma MHD generator should be arranged in the attenuation region of the magnetic induction, since arranging them in this region becomes useful for the improvement of the electrical parameters of generator.

Keywords: Numerical calculation, MHD generator, diagonal type, ballast resistance, twodimensional analysis.

\section{INTRODUCTION}

Already it has been ascertained that the performance characteristics of a diagonal type non-equilibrium plasma generator can be well approached to those of the Faraday type one by the quasi one-dimensional MHD theory $[1,2]$. However, though this theory is convenient for us to grasp the outline of the generator characteristics, it is very difficult to treat accurately the effects of the spatial nonuniformity of the working gas plasma in the generator duct cross section by the above theory.
Accordingly, by a two-dimensional analysis, the author has investigated the electrical characteristics in the central part of the diagonal type non-equilibrium plasma generator duct as described in [3], etc. Moreover, in the end regions of the MHD generators there arise the so-called end effects, and they degrade the total electrical characteristics of the generators.

Hence, up to now the end effects in the Faraday type generator have been analyzed in fair detail [4-6]. On the other hand, the end effects in the diagonal type have been only a little discussed [7-9]. Therefore, the author has investigated some influences of the 
arrangement of the output electrodes and the attenuation of the magnetic induction along the generator duct on the current and potential distributions etc. near the entrance and exist of the diagonal type MHD duct when the physical quantities in the duct are assumed to be uniform, and shown that the variation of the arrangements of output electrodes has little effect on the current distribution etc. [10]

In this paper the author studies the end effects in the diagonal type non-equilibrium plasma generator by a two-dimensional analysis. In section 2 , the basic equations and the boundary and subsidiary conditions are introduced, then, are shown configurations of the gas velocity and the applied magnetic induction that are adopted in the present paper. In section 3 , by the numerical calculations are investigated the influences of the attenuation of the magnetic induction on the current and potential distributions, the internal resistance etc. in the end regions of the generator.

\section{BASIC EQUATIONS}

\subsection{Basic equations for current distribution}

In the analysis of end effects in a diagonal type MHD generator, it is assumed that the electric quantities, such as the current, electric field etc., vary with $\mathrm{x}$ and $\mathrm{y}$, where $\mathrm{x}$ and $\mathrm{y}$ are the coordinates as shown in Fig. 1, and that the gas velocity and temperature depend on only y according to Eqs. (9) and (10) which will be presented later, and that the pressure is kept constant.
In order to evaluate the current distribution in the generator duct, we introduce the conventional stream function $\Psi$ defined by

$$
\mathrm{J}_{\mathrm{x}}=\partial \Psi / \partial \mathrm{y}, \mathrm{J}_{\mathrm{y}}=-\partial \Psi / \partial \mathrm{x}
$$

where $\mathrm{J}_{\mathrm{x}}$ and $\mathrm{J}_{\mathrm{y}}$ are the $\mathrm{x}$ and $\mathrm{y}$ components of current density, and the $\mathrm{z}$ component $\mathrm{J}_{\mathrm{z}}$ is assumed not to exist.

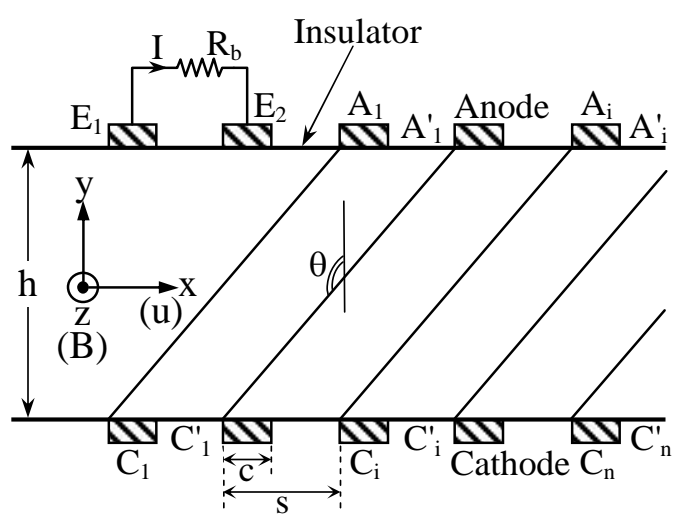

Figure 1. Coordinate system and generator duct geometry

Then, it is assumed that the magnetic induction and the gas velocity have only the $\mathrm{z}$ component $\mathrm{B}$ and the $\mathrm{x}$ component $\mathrm{u}$, respectively, from the Maxwell equations and the generalized Ohm's law which are given in Eqs. (1) and (2) in Ref. [3], we can derive the following partial differential equation:

$$
\nabla^{2} \Psi+\mathrm{P} \partial \Psi / \partial \mathrm{x}+\mathrm{Q} \partial \Psi / \partial \mathrm{y}=\mathrm{R}
$$

where

\section{Trang 64}




$$
\left.\begin{array}{c}
\mathrm{P}=\sigma / \varepsilon\{\partial(\varepsilon / \sigma) / \partial \mathrm{x}-\partial(\beta / \sigma) / \partial \mathrm{y}\} \\
\mathrm{Q}=\sigma / \varepsilon\{\partial(\varepsilon / \sigma) / \partial \mathrm{y}+\partial(\beta / \sigma) / \partial \mathrm{x}\} \\
\mathrm{R}=\sigma / \varepsilon\left\{-\partial\left(\partial \mathrm{p}_{\mathrm{e}} / \partial \mathrm{y} / \mathrm{en}_{\mathrm{e}}\right) / \partial \mathrm{x}+\right. \\
+\partial\left(\partial \mathrm{p}_{\mathrm{e}} / \partial \mathrm{x} / \mathrm{en}_{\mathrm{e}}\right) / \partial \mathrm{y}+ \\
+\mathrm{u} \partial \mathrm{B} / \partial \mathrm{x}\}
\end{array}\right\}
$$

in which $\mathrm{e}$ is the electron charge, $\mathrm{p}_{\mathrm{e}}=\mathrm{n}_{\mathrm{e}} \mathrm{kT}$ the electron partial pressure, $n_{e}$ the electron density, $\mathrm{k}$ Boltzmann's constant, $\mathrm{T}_{\mathrm{e}}$ the electron temperature, $\beta$ the Hall parameter for electron, $\beta_{\mathrm{i}}$ the Hall parameter for ion, and $\sigma$ the scalar electrical conductivity of the plasma. In addition, since $\sigma, \beta, \mathrm{n}_{\mathrm{e}}$ and $\mathrm{T}_{\mathrm{e}}$ are given in Ref. [3], we omit the explanation for them in this paper.

\subsection{Boundary and subsidiary conditions}

First, the boundary condition on the electrode surfaces is

$$
\mathrm{E}_{\mathrm{x}}=0
$$

where $E_{x}$ is the $x$ component of electric field. The one on the insulating wall surfaces is

$$
\mathrm{J}_{\mathrm{y}}=0
$$

Using Eq. (1), these conditions (4) and (5) are transformed to

$$
\begin{gathered}
\varepsilon \partial \Psi / \partial \mathrm{y}-\beta \partial \Psi / \partial \mathrm{x}-\sigma \partial \mathrm{p}_{\mathrm{e}} / \partial \mathrm{x} / \mathrm{en}_{\mathrm{e}}=0 \\
\Psi=\mathrm{const} \quad\left(5^{\prime}\right)
\end{gathered}
$$

Next, in the diagonal type generator, the potential difference must be zero between the anode $A_{i}$ and cathode $C_{i}$ which are shorted each other as shown in Fig. 1. Therefore, the first subsidiary condition is obtained as

$\mathrm{V}_{\mathrm{i}}=-\int_{\mathrm{A}_{\mathrm{i}}}^{\mathrm{C}_{\mathrm{i}}} \mathrm{Eds}=0, \mathrm{i}=1,2, \ldots, \mathrm{n}$ where $\mathrm{E}$ is the electric field intensity vector, ds the line element vector of an optional integral path from $A_{i}$ to $C_{i}$, and $V_{i}$ the potential difference between $A_{i}$ and $C_{i}$.

As the current which runs through an arbitrary surface $S_{i}$ crossing the insulating wall surfaces $\mathrm{A}_{\mathrm{i}}^{\prime}$ and $\mathrm{C}_{\mathrm{i}}^{\prime}$ is equal to the load current I, the second subsidiary condition is written as

$$
\int_{\mathrm{S}_{\mathrm{i}}} \mathrm{JdS}=\mathrm{I}, \mathrm{i}=1,2, \ldots, \mathrm{n}
$$

where dS is the element vector of the surface $\mathrm{S}_{\mathrm{i}}$.

Lastly, let us assume that the electric quantities vary periodically in the period of the electrode pitch $\mathrm{s}$ along the gas flow behind the $n$-th electrode pair $A_{n}$ and $C_{n}$. Then the condition for the current density $\mathrm{J}(\mathrm{x})$ is given by

$$
\mathrm{J}(\mathrm{x}+\mathrm{s})=\mathrm{J}(\mathrm{x})
$$

By Eq. (1), the Eq. (8) is transformed into

$$
\Psi(\mathrm{x}+\mathrm{s})=\Psi(\mathrm{x})+\mathrm{I}_{\mathrm{y}}^{(\mathrm{n})}
$$

where $I_{y}^{(n)}$ is the current flowing into $A_{n}$.

The current distributions in the diagonal type generator can be found by numerically solving Eq. (2) under the conditions $\left(4^{\prime}\right) \sim(7)$ and $\left(8^{\prime}\right)$ (see section 3 ).

\subsection{Calculation of potential}

When Eq. (2) is numerically solved under the conditions $\left(4^{\prime}\right) \sim(7)$ and $\left(8^{\prime}\right)$, the electric field $\mathrm{E}$ at the optional point can be evaluated by Eq. (1) and the generalized Ohm's law, with the obtained numerical solution of $\Psi$. Then the potential at any point can be calculated by the 
numerical line integration of $\mathrm{E}$ along an arbitrary integral path from a reference point to the considered point.

\subsection{Gas velocity and temperature distributions}

As assumed in section 2, the velocity $u$ has only the $\mathrm{x}$ component $\mathrm{u}$, and $\mathrm{u}$ and $\mathrm{T}$ vary only in the $\mathrm{y}$ direction according to the following relation [11]

$$
\begin{gathered}
\mathrm{u} / \mathrm{u}_{0}=\{4 \mathrm{y} / \mathrm{h}(1-\mathrm{y} / \mathrm{h})\}^{\mathrm{m}} \\
\left(\mathrm{T}-\mathrm{T}_{\mathrm{w}}\right) /\left(\mathrm{T}_{0}-\mathrm{T}_{\mathrm{w}}\right)=\{4 \mathrm{y} / \mathrm{h}(1-\mathrm{y} / \mathrm{h})\}^{\mathrm{n}}
\end{gathered}
$$

respectively, where $\mathrm{h}$ is the duct height, $\mathrm{u}_{0}$ and $\mathrm{T}_{0}$ are the gas temperature and velocity at the center of flow, namely $\mathrm{y}=\mathrm{h} / 2$ and $\mathrm{T}_{\mathrm{w}}$ is the wall temperature.

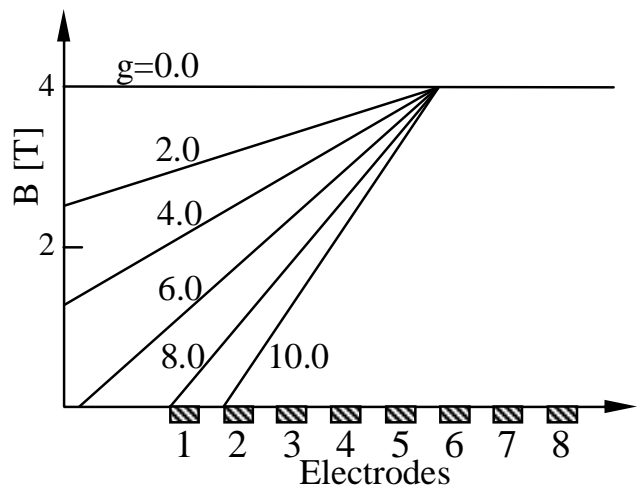

Figure 2. Configuration of applied magnetic induction

\subsection{Configuration of Applied Magnetic Induction}

For effective use of the applied magnetic flux density $\mathrm{B}$, the MHD generator duct may be arranged in the attenuation region of $\mathrm{B}$. So in order to investigate the influence of the configuration of $\mathrm{B}$ on the current distribution in the end regions of the diagonal type generator, we assume that the intensity of B is constant in the central region and decreases linearly from the left edge of the $\mathrm{j}$-th electrode in the end regions of the generator. In this connection in this numerical analysis, the author assumes the six configurations of $\mathrm{B}$ as plotted in Fig. 2, where $g$ is the gradient of $B$ and $j=5$.

\section{NUMERICAL METHOD FOR SUBSIDIARY CONDITIONS}

In a diagonal generator, the solution of Eq. (3) is required to satisfy the two subsidiary conditions (6) and (7). From Eqs. (1) and (7), we can derive the following equation:

$$
\Psi_{\mathrm{i}}^{\mathrm{A}^{\prime}}-\Psi_{\mathrm{i}}^{\mathrm{C}^{\prime}}=\mathrm{I} / \mathrm{w}, \mathrm{i}=1,2, \ldots, \mathrm{n}(11)
$$

where $\Psi_{\mathrm{i}}^{\mathrm{A}^{\prime}}$ and $\Psi_{\mathrm{i}}^{\mathrm{C}^{\prime}}$ are the values of $\Psi$ on the insulating wall surfaces $\mathrm{A}_{\mathrm{i}}{ }^{\prime}$ and $\mathrm{C}_{\mathrm{i}}{ }^{\prime}$ respectively, and $\mathrm{w}$ is the duct width in the $\mathrm{z}$ direction.

First, if the values of I and $\mathrm{w}$ are assumed and $\Psi_{\mathrm{i}}^{\mathrm{A}^{\prime}}$ are given plausible values, the values of $\Psi_{\mathrm{i}}^{\mathrm{C}^{\prime}}$ are decided by Eq. (11). When Eq. (2) is digitally solved with these values of $\Psi_{\mathrm{i}}^{\mathrm{A}^{\prime}}$ and $\Psi_{\mathrm{i}}^{\mathrm{C}^{\prime}}$ and the appropriately assumed values of $\mathrm{u}, \sigma$ and $\beta$, we can obtain the numerical solution of $\Psi$. By applying the solution to Eq. (1) and the generalized Ohm's law, we can find the values of $E_{x}$ and $E_{y}$. Further, by substituting the values of $E_{x}$ and $E_{y}$ into the integral in Eq. (6), we can decide the value of $\mathrm{V}_{\mathrm{i}}$. Then the value of $\mathrm{V}_{\mathrm{i}}$ obtained is not necessarily equal to zero.

\section{Trang 66}


Let us consider the resistance between the electrodes $\mathrm{A}_{\mathrm{i}}$ and $\mathrm{C}_{\mathrm{i}}$

$\mathrm{R}_{\mathrm{i}}^{\prime}=\mathrm{h} /\left\{\langle\sigma\rangle_{\mathrm{i}} \mathrm{cw} \cos (\pi-\theta)\right\}, \mathrm{i}=1,2, \ldots, \mathrm{n}$

where $\mathrm{h}, \mathrm{c}$ and $\theta$ are the duct height, the electrode width and the angle of inclination to the $y$ axis of the lines joining the equipotential electrodes, respectively, and we assume that an imaginary current defined by

$$
\mathrm{I}_{\mathrm{i}}=\mathrm{V}_{\mathrm{i}} / \mathrm{R}_{\mathrm{i}}^{\prime}, \mathrm{i}=1,2, \ldots, \mathrm{n}
$$

flows through the resistance $R_{i}{ }^{\prime}$. To make $V_{i}$ zero, it is needed to flow the inverse current $-\mathrm{I}_{\mathrm{i}}$ through $\mathrm{R}_{\mathrm{i}}$. Then it is required to increase by $-\mathrm{I}_{\mathrm{i}}$ the value of $\mathrm{w}\left(\Psi_{\mathrm{i}+1}^{\mathrm{A}^{\prime}}-\Psi_{\mathrm{i}}^{\mathrm{A}^{\prime}}\right)$, which gives the current running into the anode $\mathrm{A}_{\mathrm{i}}$.

Again beginning with the new modified values of $\Psi_{\mathrm{i}}^{\mathrm{A}^{\prime}}$, we must repeat the above mentioned calculation process. When $\mathrm{V}_{\mathrm{i}}$ becomes adequately small after the many repetitions of the above mentioned process, at last we can obtain the satisfactory numerical solution of $\Psi$.

In connection, the other parts of numerical calculation processes are explained in Ref. [12].

\section{NUMERICAL CALCULATION}

\subsection{Numerical Conditions}

Numerical analysis is carried out for the diagonal type MHD generator with the cesium seeded helium in non-equilibrium ionization in which $\mathrm{h}=0.2, \mathrm{~s}=0.1, \mathrm{w}=0.1, \mathrm{c}=0.06 \mathrm{~m}$

$\mathrm{T}_{0}=1800 \mathrm{~K}, \mathrm{~T}_{\mathrm{w}}=1600 \mathrm{~K}, \mathrm{p}=5 \mathrm{~atm}$

$\mathrm{u}_{0}=2000 \mathrm{~m} / \mathrm{s}, \mathrm{m}=\mathrm{n}=1 / 7, \mathrm{~B}_{0}=4$ or $5 \mathrm{~T}$

$\delta=5, \varepsilon_{\mathrm{s}}=0.3 \%$

where $\varepsilon_{\mathrm{s}}$ is the seed fraction of $\mathrm{C}_{\mathrm{s}}, \mathrm{B}_{0}$ the magnetic induction in the central region of generator duct, and $\delta$ the collision loss factor. These conditions are assumed with respect to a generator of the pilot plant [13]. The load current $\mathrm{I}$ is assumed to flow equally into two output electrodes $E_{1}$ and $E_{2}$ through a ballast resistance $\mathrm{R}_{\mathrm{b}}$ defined by (see Fig. 1)

$$
\mathrm{R}_{\mathrm{b}}=-\int_{\mathrm{E}_{1}}^{\mathrm{E}_{2}} \mathrm{Eds} /(\mathrm{I} / 2)
$$

\subsection{Calculation Results}

In Figs. 3a c, the current distributions are plotted in the case of $\mathrm{g}=0,6$ and $10 \mathrm{~T} / \mathrm{m}$, respectively, $B_{0}=4 T$ and $I=70 A$, where the contour interval of current streamlines is $1 / 20$ of the load current I. In the figures, $\langle\mathrm{J}\rangle_{\mathrm{el}}=$ $0.583 \mathrm{~A} / \mathrm{cm}^{2},\langle\sigma\rangle=1.84 \mathrm{mho} / \mathrm{m},\langle\beta\rangle=2.01$ and $\beta_{\text {crit }}=2.48$, where $\langle\mathrm{J}\rangle_{\mathrm{el}}$ is the average current density on the output electrodes, $\langle\sigma\rangle$ and $\langle\beta\rangle$ are the average electrical conductivity and Hall parameter in the center of flow, respectively, $\beta_{\text {crit }}$ is the critical Hall parameter [14].

Figure 3(a) shows that the current concentration at the edges of the output electrodes is very intensive when $\mathrm{B}$ does not attenuate. On the other hand, Figs. 3(b) and (c) indicate that the concentration weakens as the attenuation of $\mathrm{B}$ increases, since $\beta$ becomes small in the area suffering a spatial reduction of B. Also it is seen that the current flowing into a 
diagonally connected electrode pair reduces with increasing the gradient of the magnetic induction in the entrance region of duct, for instance, the currents of about 60, 25 and $15 \%$ of I flow into $\mathrm{C}$, when $\mathrm{g}=0,6$ and $10 \mathrm{~T} / \mathrm{m}$, respectively. Also the figures denote that the eddy current is not induced when the output electrodes are disposed in the region of the attenuating magnetic induction [5], and that arranging the output electrodes within the attenuation region of $\mathrm{B}$ does not have a great influence on the current distribution in the central part of generator duct.

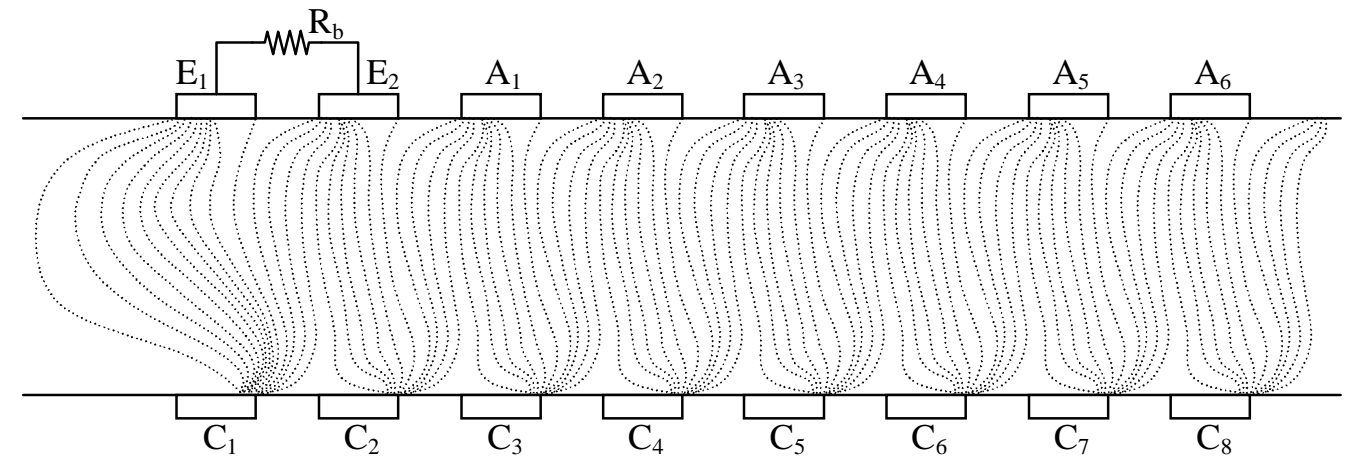

(a) $g=0, B_{0}=4$

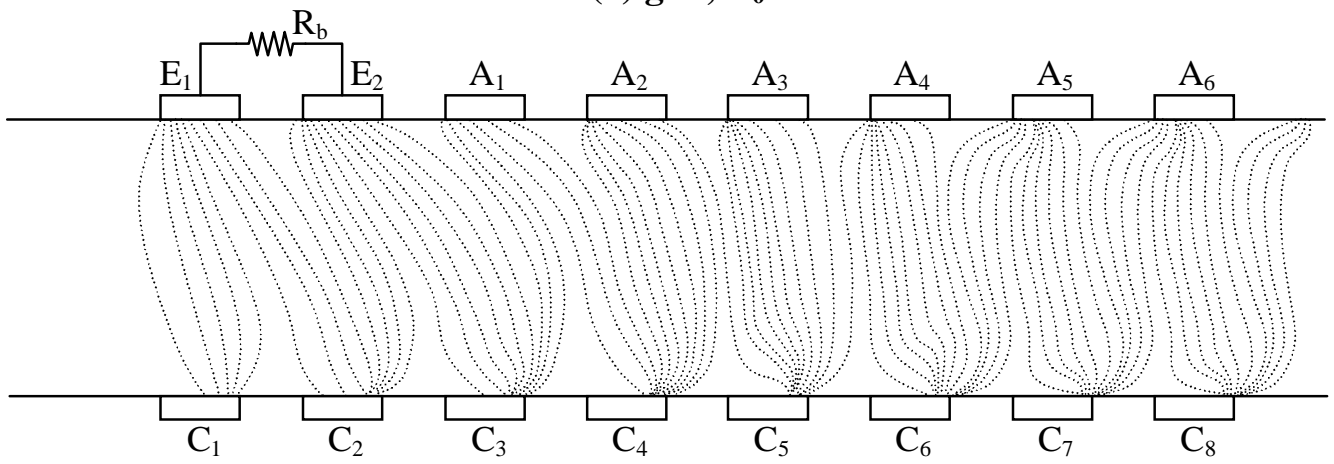

(b) $g=6, B_{0}=4$

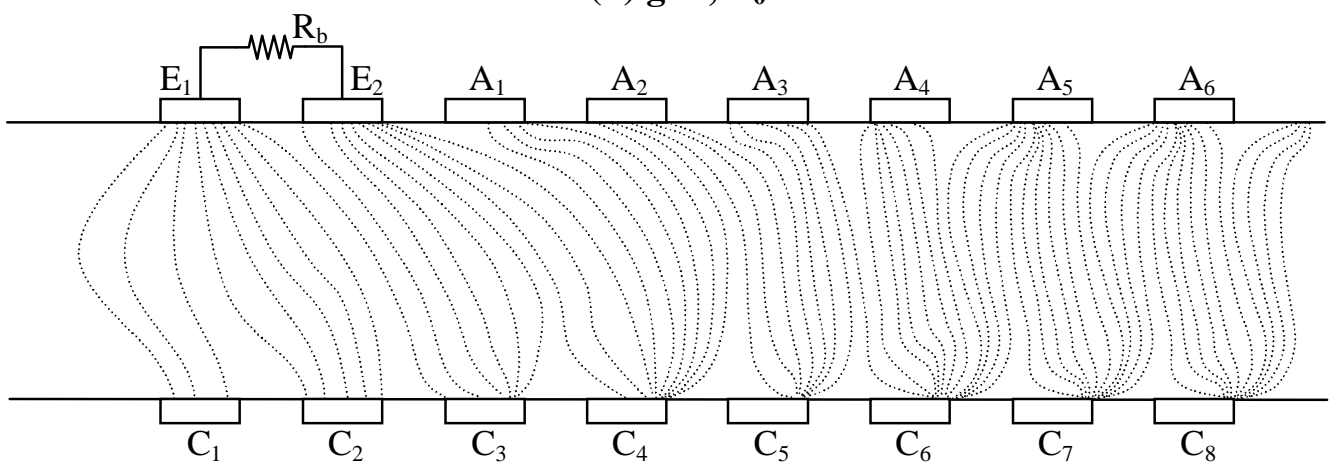

(c) $\mathrm{g}=10, \mathrm{~B}_{0}=4$

Figure 3. Current distributions 


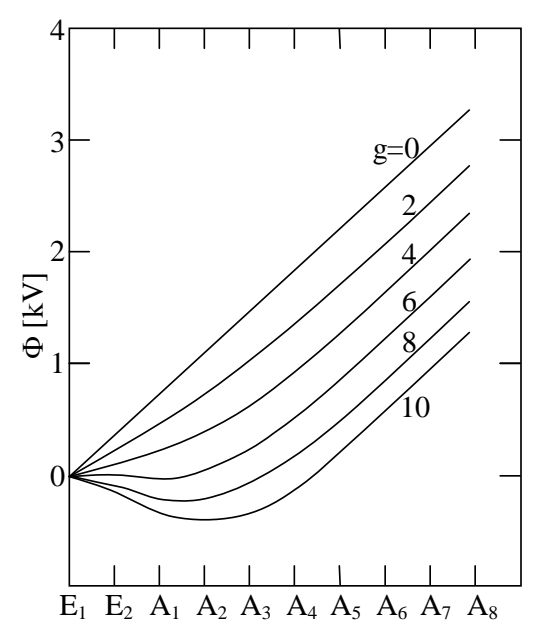

Figure 4. Variation of potential difference

$$
\text { for } \mathrm{B}_{0}=4
$$

Next, Fig. 4 shows the variation of the potential difference between the electrode pairs $A_{1}-C_{1} \sim A_{8}-C_{8}$ and the electrode $E_{1}$. From the figures it is seen that the relatively large potential difference arises between the two output electrodes $\mathrm{E}_{1}$ and $\mathrm{E}_{2}$ when $\mathrm{B}$ does not attenuate, namely $g=0$. On the other hand, the potential difference become smaller as $g$ becomes larger, it almost vanishes for $g=6$, and the inverse difference appears for $g>7$. Also Fig. 4 denotes that the potential differences in the central part of generator duct are little influenced by the decrease of the magnetic induction.

Next, for estimation of the end effects of the generator, the author evaluates the internal resistance $R_{i}$ of the end regions and the grade of the current concentration on the output electrodes given by the relations

$$
\begin{aligned}
& \mathrm{R}_{\mathrm{i}}=\left(\mathrm{V}_{0}-\mathrm{V}\right) / \mathrm{I} \\
& \mathrm{J}_{\text {peak }} /\langle\mathrm{J}\rangle_{\mathrm{el}} \geq 1
\end{aligned}
$$

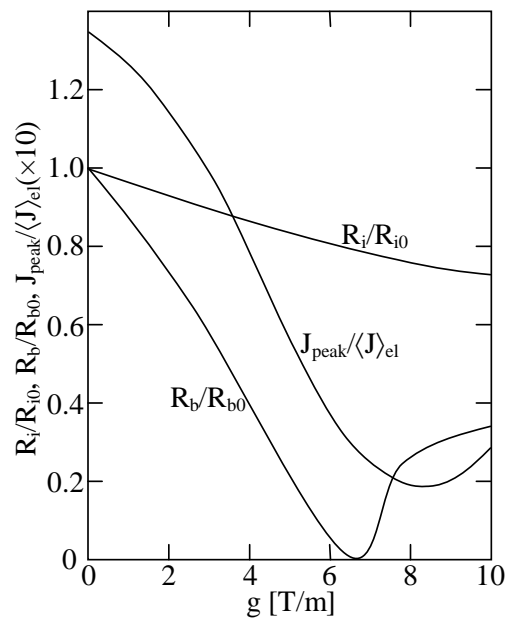

Figure 5. Influence of $g$ on $\mathrm{R}_{\mathrm{i}} / \mathrm{R}_{\mathrm{i} 0}, \mathrm{R}_{\mathrm{b}} / \mathrm{R}_{\mathrm{b} 0}$ and $\mathrm{J}_{\text {peak }} /\langle\mathrm{J}\rangle_{\mathrm{el}}$

$$
\text { when } \mathrm{B}_{0}=4
$$

where $\mathrm{V}_{0}$ and $\mathrm{V}$ are no-load and load potential difference between the output electrode $E_{1}$ and the $n$-th electrode, respectively, and $J_{\text {peak }}$ is the maximum current density on the output electrodes. In this connection, $\mathrm{J}_{\text {peak }} /\langle\mathrm{J}\rangle_{\mathrm{el}}=1$ means the state of no current concentration and $\mathrm{J}_{\text {peak }} /\langle\mathrm{J}\rangle_{\mathrm{el}}>>1$ does the intensive current concentration at an electrode edge.

Now Fig. 5 shows the variations of $R_{i} / R_{i 0}$, $\mathrm{R}_{\mathrm{b}} / \mathrm{R}_{\mathrm{b} 0}$ and $\mathrm{J}_{\text {peak }} /\langle\mathrm{J}\rangle_{\mathrm{el}}$ by $\mathrm{g}$, where $\mathrm{R}_{\mathrm{i} 0}$ and $\mathrm{R}_{\mathrm{b} 0}$ are $R_{i}$ and $R_{b}$ for $g=0$, respectively. From the figure, it is seen that $R_{i}$ decreases with $g$, for instance the value of $R_{i}$ for $g=6.0$ becomes about $80 \%$ of the one of $\mathrm{R}_{\mathrm{i} 0}$, and that $\mathrm{J}_{\text {peak }} /\langle\mathrm{J}\rangle_{\mathrm{el}}$ decreases from $\mathrm{g}=0$ to $8 \mathrm{~T} / \mathrm{m}$, reaches the minimum value 1.90 and increases again. This fact shows that the current concentration at the edges of the output electrodes is almost diminished when $g=8 \mathrm{~T} / \mathrm{m}$. Accordingly, arranging the output electrodes in the attenuation area of the magnetic flux density is 
useful to guard the output electrodes. Also Fig.

5 tells that $\mathrm{R}_{\mathrm{b}} / \mathrm{R}_{\mathrm{b} 0}$ decreases with $\mathrm{g}$, becomes almost zero for $\mathrm{g}=6.5$ and then increases with

g. Therefore, it is shown that many output electrodes will require large ballast resistors when B does not attenuate or exceeds 8 , but they can be used without large ballast resistors in the range of $g=6 \sim 7 \mathrm{~T} / \mathrm{m}$.

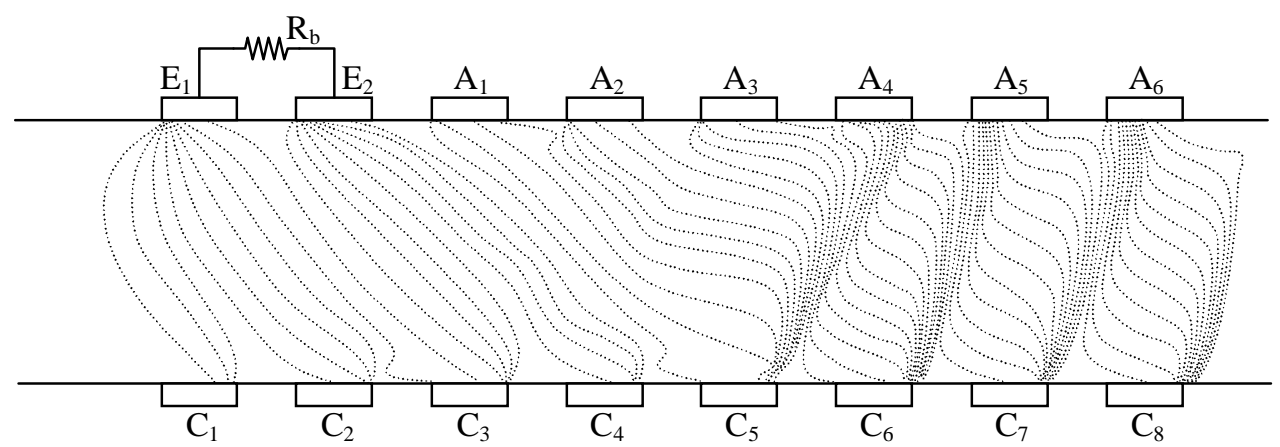

Figure 6. Current distribution for $\mathrm{g}=6$ and $\mathrm{B}_{0}=5$

In Fig. 6, the current distribution is plotted when $\mathrm{g}=6 \mathrm{~T} / \mathrm{m}, \quad \mathrm{B}_{0}=5 \mathrm{~T}$ and $\mathrm{I}=150 \mathrm{~A}$, $\langle\mathrm{J}\rangle_{\mathrm{el}}=1.25 \mathrm{~A} / \mathrm{cm}^{2},\langle\sigma\rangle=2.85 \mathrm{mho} / \mathrm{m},\langle\beta\rangle=2.48$ and $\beta_{\text {crit }}=1.90$. The figure indicates that the streamer is induced in the central part of generator, while the current distribution becomes successively uniform as B attenuates along the generator duct and the current concentration is almost swept away near the output electrodes. Therefore it is seen that arranging the output electrodes within the attenuating region of $\mathrm{B}$ is effective for the case where the streamer is generated in the central region of generator duct, too.

\section{CONCLUSIONS}

The main conclusions derived from the above described numerical calculation are as follows:

1. A suitable distribution of the magnetic flux density can make the current distribution very uniform near the end region of generator duct, both when the streamer is not induced and when it is induced in the central region.

2. Disposing the output electrodes within the attenuation area of magnetic flux density has little influence on the current distribution in the central part of generator duct.

3. When the output electrodes are disposed in the region with a suitably reduced magnetic flux density, the potential difference and the ballast resistance between two output electrodes become very small. Accordingly it is thought that many output electrodes can be used without large ballast resistors.

4. The internal resistance in the end region of the generator duct decreases as the magnetic flux density attenuates.

Trang 70 
5. The current concentration at the edges of output electrodes can be fairly eliminated by attenuating magnetic flux density.

As mentioned above, it is made clear that the output electrodes of the diagonal type non- equilibrium plasma MHD generator should be arranged in the region of the attenuating magnetic flux density, since arranging them in the region of the decreasing magnetic flux density become useful for the improvement of the electrical characteristics of the generator.

\section{PHÂN TÍCH ẢNH HƯởNG CỦA SỰ SUY GIẢM CẢM ỨNG TỪ ĐẾN SỰ PHÂN BỐ DÒNG ĐIỆN TRONG MÁY PHÁT ĐIỆN TỬ THỦY ĐộNG LOẠI FARADAY}

\section{Le Chi Kien}

Ho Chi Minh City - University of Technical Education

TÓM TĂT: Bài báo nghiên cứu ảnh hưởng của sụ suy giảm của cảm ứng tù̀ đến sự phân bố dòng điện trong vùng phía cuối của máy phát điện Tù thuỷ động loại điện cực chéo dùng plasma không cân bằng bằng phân tích hai chiều. Nhũng tính toán số đã được thực hiện cho truờng hợp khí làm việc hê-li được cấy thêm xê-zi. Kết quả là một sư suy giảm phù hợp của cảm ứng tù có thể tạo ra sư phân bố dòng điện rất đồng nhất gần khu vục cuối của ống dẫn máy phát điện, và ảnh huởng nhỏ đến phân bố dòng điện ở khu vục giũa, và điện cực đầu ra có thể được dùng mà không cần điện trở cân bằng lớn. Điện trở nội của vùng cuối và sụ tập trung dòng điện tại điện cục đầu ra cũng giảm cùng với sư suy giảm của mật độ tù thông. Theo nhu khảo sát được tù bài báo, rõ ràng là điện cực đầu ra của máy phát điện Tù̀ thuỷ động loại điện cục chéo dùng plasma không cân bằng nên được sắp xếp trong khu vục suy giảm của cảm ứng tù bởi vì việc sắp xếp này sẽ trở nên hưu ich trong việc cải thiện những thuộc tính điện của máy phát.

\section{REFERENCES}

[1]. H. Yamaguchi, Y. Hisazumi, H. Asano, H. Morita, T. Hori, T. Matsumoto, T. Abiko,

A New Heat Supply System of Cogeneration for the Local Community, JSME Journal of Power and Energy Systems, 2, 3, 1085-1095 (2008).
[2]. Y. Hamada, K. Amazawa, S. Murakawa, H. Kitayama, M. Nabeshima, H. Takata, Study on Operation Characteristics and Performance Evaluation of Residential Combined Heat and Power System, JSER 27th International Conference on Energy, Economy, and Environment, 7-1, 453-458 (2011). 
[3]. S. Mori, H. Akatsuka, M. Suzuki, Numerical Analysis of Carbon Isotope Separation by Plasma Chemical Reactions in Carbon Monoxide Glow Discharge, Journal of Nuclear Science and Technology, 39, 6, 637-646 (2002).

[4]. V.A. Bityurin, MHD Electrical Power Generation in a T-Layer Plasma Flow, IEEE Transactions on Plasma Science, 28, 3, 1020-1028 (2000).

[5]. S.M. Aithal, Shape Optimization of a MHD Generator Based on Pressure Drop and Power Output Constraints, International Journal of Thermal Sciences, 47, 6, 778-786 (2008).

[6]. S.M. Aithal, Characteristics of Optimum Power Extraction in a MHD Generator with Subsonic and Supersonic Inlets, Energy Conversion and Management, 50, 3, 765-771 (2009).

[7]. M. Anwari, N. Sakamoto, T. Hardianto, J. Kondo, N. Harada, Numerical Analysis of Magnetohydrodynamic Accelerator Performance with Diagonal Electrode Connection, Energy Conversion and Management, 47, 13-14, 1857-1867 (2006).

[8]. Motoo Ishikawa, Fumiki Inui, Juro Umoto, Fault Analysis of a Diagonal Type MHD Generator Controlled with Local Control Circuit, Energy Conversion and Management, 40, 3, 249-260 (1999).
[9]. B.S. Bhadoria, A. Chandra, Transient Analysis of Proposed Indian MHD Channel, Energy Conversion and Management, 42, 8, 963-966 (2001).

[10]. Y. Inui, H. Ito, T. Ishida, Two Dimensional Simulation of Closed Cycle Disk MHD Generator Considering Nozzle and Diffuser, Energy Conversion and Management, 45, 13-14, 1993-2004 (2004).

[11]. Y. Gelfgat, J. Krūminš, B.Q. Li, Effects of System Parameters on MHD Flows in Rotating Magnetic Fields, Journal of Crystal Growth, 210, 4, 788-796 (2000)

[12]. E. M. Braun, R. R. Mitchell, A. Nozawa, D. R. Wilson, F. K. Lu, J. C. Dutton, Electromagnetic Boundary Layer Flow Control Facility Development Using Conductive Nanoparticle Seeding, 46th Aerospace Sciences Meeting and Exhibit, AIAA Paper 2008-1396 (2008).

[13]. Lingen Chen, Jianzheng Gong, Fengrui Sun, Chih Wu, Heat Transfer Effect on the Performance of MHD Power Plant, Energy Conversion and Management, 43, 15, 2085-2095 (2002).

[14]. E. Sawaya, N. Ghaddar, F. Chaaban, Evaluation of the Hall Parameter of Electrolyte Solutions in Thermosyphonic MHD Flow, International Journal of Engineering Science, 40, 18, 2041-2056 (2002). 